\title{
Effect of Electron-Plasma Treatment on the Microstructure of Al-11wt\%Si Alloy
}

\author{
Dmitrii Zaguliaev ${ }^{a, b}$, Yurii Ivanov ${ }^{c}$, Sergey Konovalov ${ }^{a, d *}$ (1), Anna Abaturova ${ }^{b}$, Victor Gromov ${ }^{b}$, \\ Yulia Rubannikova ${ }^{b}$, Alexander Semin ${ }^{b}$ \\ ${ }^{a}$ Wenzhou University Institute of Laser and Optoelectronic Intelligent Manufacturing, 325024, \\ Wenzhou, China \\ ${ }^{b}$ Siberian State Industrial University, 654007, Novokuznetsk, Russia \\ ${ }^{c}$ Institute of High Current Electronics of the Siberian Branch of the RAS, 634055 Tomsk, Russia \\ ${ }^{d}$ Samara National Research University, 443086 Samara, Russia
}

Received: February 7, 2020; Revised: April 6, 2020; Accepted: April 10, 2020

\begin{abstract}
The analysis of structure, defect substructure, elemental and phase compounds and friction properties of Al- $11 \mathrm{wt} \% \mathrm{Si}$ alloy surface layer of subjected to complex treatment was carried out by methods of scanning and transmission electron microscopy. Complex treatment includes the electroexplosion influence by $\mathrm{Al}-\mathrm{Y}_{2} \mathrm{O}_{3}$ compound and subsequent electron beam irradiation. The surface layer $\approx 80 \mu \mathrm{m}$ thick is formed by high-velocity crystallization cells of $0.8-1.3 \mu \mathrm{m}$ in dimension. Interlayers $50-75 \mathrm{~nm}$ thick located along the cells of high-velocity crystallization are enriched by atoms of silicon and yttrium. Complex surface treatment leads to the increase by 18 times in wear resistance and decrease by 1.6 times in the friction factor of the modified layer.
\end{abstract}

Keywords: Al-11wt\%Si alloy; pulsed electron beam treatment; electroexplosive treatment; structure; tribological properties.

\section{Introduction}

In paper ${ }^{1}$ it is claimed that alloys based on Al-Si system are the most spread aluminum casting alloys and are widely used as modern structural materials in automobile, aerospace and other fields of industry where a good strength, light weight, high corrosion resistance and good ability for casting are needed. In the work ${ }^{2}$ it is defined that the casting alloys as the materials being used for the manufacturing of mould castings are the products made of aluminum alloy with complex geometrical shape. The low-alloyed high-strength aluminum casting alloy Nickalyn-AZ6NF (of Al-Zn-Mg-Fe-Ni system) based on (Al) + A19FeNi eutectic as a promising material used for manufacturing of shaped castings is described in Mann et al. ${ }^{3}$. As the authors indicate the main advantages of Nickalyn-AZ6NF alloy are a high level of mechanical properties (the ultimate tensile strength reaches $500 \mathrm{MPa}$ ), a good workability at casting and a relatively low prime cost.

The wide use of aluminum alloys and composites based on aluminum matrix in industry is explained by their relatively low cost and a rather high specific strength. In the paper ${ }^{4}$ aluminum alloys by stir-squeeze casting are obtained. Four variants of obtaining the aluminum composites were used: ( $\mathrm{AlSi}_{7} \mathrm{Mg}+$ alumina; scrap aluminum alloy + alumina; $\mathrm{AlSi}_{7} \mathrm{Mg}+$ spent alumina catalyst; scrap aluminum alloy + spent alumina catalyst). Scrap aluminum alloy obtained from aluminum wheel disks or $\mathrm{AlSi}_{7} \mathrm{Mg}$ were used as a base material. Spent alumina catalysts being a product of oil refineries or alumina were added to the melt as reinforcement material. Composites obtained by

*e-mail:ksv@ssau.ru,ksv@wzu.edu.cn stir-squeeze casting of scrap aluminum alloy and alumina were characterized by the best properties, namely: they exhibited the lowest porosity (7.3\%) and abrasive wear loss ( $0.11 \mathrm{mg}$ for the finest abrasive), high hardness (58.5 BHN) as well as high ultimate tensile strength (UTS) (125 MPa) and ultimate compression strength (UCS) (312 MPa) as compared to other variants of obtaining the composites.

The mechanical properties of 6063-T5 and 6061-T6 aluminum alloys at increased temperatures are studied ${ }^{5}$. In the paper the following properties: the yield point, Young modulus and ultimate tensile strength are determined experimentally. It was suggested to unify the equation for calculation of the mechanical properties of aluminum alloys at elevated temperatures. The dependences established in the research give the more accurate values of calculated magnitudes as compared to the existing regularities.

In most cases, it is enough to harden the surface layer of the materials without resorting to the bulk hardening. The modification of the surface layer of metal products serves for the increase in mechanical and tribological properties. The increase in wear resistance by rubbing is presented in a scientific study ${ }^{6}$. The method consists in introduction of hard particles into a bulk material by friction. An aluminum alloy (duralumin) was used as bulk material and tungsten carbide (WC) was used in the form of hard particles. The fretting tests were performed in both dry and oil-lubricated conditions. The surface modification improves the fretting wear resistance of aluminum alloy. The increase in wear resistance without changing abrasive wear possible thanks mixing of fine particles in the metal matrix. 
The method of surface alloying of metallic materials using the electric explosion of conductors is also known. Electroexplosion alloying enables one to increase in hardness, durometric and tribological properties in a modified material. Hardening is reached by means of formation of hardening coating consisting of fine-dispersed phases. It is claimed ${ }^{7}$ that the properties of the resultant coating are strongly dependent on microstructure, phase composition, porosity and its distribution.

In the paper ${ }^{8} \mathrm{Ti}-\mathrm{Zr}$ coating on the surface of tooth implant made of VT6 using electric explosion was obtained. It was established that the formed coating was a multiphase and multielemental one, its thickness was less than $50 \mu \mathrm{m}$. The increase in friction factor by 1.5 times and the decrease in wear parameter by $18 \%$ were observed.

One of promising directions of creation of modern structural materials is the formation of ultrafine-grained or nanocrystalline structure in volume or on surface of a material. Study of the formation of aluminum nanocrystals in light-weight amorphous alloys A190Y10 and A187Ni8Gd5 on heating and under deformation by the methods of X-ray diffraction and electron microscopy was performed in the reference? The average size of nanocrystals in the deformed and annealed sample amounted to $9 \mathrm{~nm}$ that was the intermediate one between the average size of nanocrystals formed as a result of deformation $(6 \mathrm{~nm})$ and under heat treatment $(23 \mathrm{~nm})$ was detected. Thus, the combined treatment forms a nanostructure with intermediate size of structural components which are between the sizes of nanocrystals only in the deformed and only in annealed alloys. The change in volume fraction of nanocrystals leads to the variation in microhardness. With the increase in deformation degree the volume fraction of nanocrystalline phase increases. The maximum value of microhardness amounted to $4.5 \mathrm{GPa}$ which corresponds to yield point of $1.5 \mathrm{GPa}$. The value is very close to the maximum value being observed in amorphous nanocrystalline alloy based on Al.

In recent years the attention of researchers in the field of physical materials science is concentrated on the analysis of nature of metals' and alloys' hardening under the action of the external energy influences and concentrated flows of energy $y^{10-15}$. The promising field of development is a combination of several methods of modification.

The study of microstructure and properties of steel surface layer alloyed by chromium using the method of magnetron spraying followed by processing with high-current pulsed electron beam was performed in the research ${ }^{15}$. Different thickness of preliminary applied film of chromium followed by the electron beam irradiation with energy density of $4.4 \mathrm{~J} \mathrm{~cm}^{-2}$ and 100 pulses was studied. The authors established that the optimum thickness of preliminary applied film of chromium amounted to $600 \mathrm{~nm}$ and microcracks appeared only when $\mathrm{Cr}$ film thickness increased $800 \mathrm{~nm}$. Micro cracks were caused by increasing residual stresses after ultrafast heat cycles. After processing by high-current pulsed electron beam the remelted layer may be divided into three layers: the first layer consists of $\mathrm{Fe}-\mathrm{Cr}$ solid solution and a small quantity of nanodimensional amorphous phase being formed in the boundaries of subgrains; in the second layer the columnar grains of austenite may be observed, in the third layer there are only plates of martensite. As a result of such a processing the microhardness of the surface layer alloyed by chromium changed insignificantly as compared to the initial steel substrate, however corrosion resistance increased considerably.

At the paper ${ }^{16}$ the results of investigation into wear resistance of aluminum alloy with high content of $\mathrm{Si}, \mathrm{Fe}$ and $\mathrm{Cu}$ after combined treatment of surface involving the plasma nitriding followed by electron beam remelting were presented. In order to avoid the loss of hardness during the thermal cycle of nitriding in plasma $\left(480^{\circ} \mathrm{C}\right)$ the consecutive processing: plasma nitriding followed by electron beam remelting was used. As a result of the complex treatment the authors succeeded in increasing in wear resistance of the material almost by 10 times.

The electron beam irradiation technique is widely used in branches of industry in welding process. Some researchers employ the method of electron beam irradiation for manufacturing of metal/oxide nanocomposite materials ${ }^{17}$. At first, $\mathrm{CoO}$ films were obtained by pulsed laser deposition method and then the resultant films were irradiated by electron beam. By means of this technique the cobalt oxide is possible to be reduced to metallic $\mathrm{Co}$ and $\mathrm{Co} / \mathrm{CoO}$ nanocomposite. In this case the parameters of structure of the obtained materials can be controlled by changing in energy density of electrons and time of irradiation.

Having carried out the review of modern state of researches in the field of modification of structure and properties of the materials based on aluminum it may be stated that this direction of investigations is a relevant one and it requires further development. The importance of improvement in the service characteristics of alloys based on aluminum is dictated by practical requirements as well because aluminum alloys gradually replace steel in manufacturing of parts and units for different purposes.

Our research team had already performed investigations into changes in structure of silumin surface layer treated by pulsed electron beam in six different modes ${ }^{18}$. Moreover, we determined the effect of electroexplosive alloying by Al- $\mathrm{Y}_{2} \mathrm{O} 3$ system ( 6 modes) on structure, phase composition and mechanical properties of Al-Si alloy ${ }^{19}$. For each of the modification methods the optimal parameters were determined: for pulsed electron beam treatment they are energy densities of $25,30,35 \mathrm{~J} / \mathrm{cm}^{2}$; for electroexplosion alloying they are Mode 2 (discharge voltage - $2.8 \mathrm{kV}$, weight of aluminum foil - $0.0589 \mathrm{~g}$, weight of yttrium powder $\mathrm{Y}_{2} \mathrm{O}_{3}-0.0589 \mathrm{~g}$.), and Mode 5 (discharge voltage $-2.6 \mathrm{kV}$, weight of aluminum foil - $0.0589 \mathrm{~g}$, weight of yttrium powder $\mathrm{Y}_{2} \mathrm{O}_{3}-0.0883 \mathrm{~g}$.). Combination of regimes 2 and 5 with subsequent electron beam irradiation at energy density of electron beam $35 \mathrm{~J} / \mathrm{cm}^{2}$ was carried out in paper $^{20}$. This paper continues our research started in ${ }^{18-21}$.

The purpose of the research is to analyze the structure, defect substructure, elemental and phase compounds and friction properties of surface layer of $\mathrm{Al}-11 \mathrm{wt} \% \mathrm{Si}$ alloy samples irradiated by pulsed electron beam (density of electron beam $-25 \mathrm{~J} / \mathrm{cm}^{2}$ ) and subjected to the electroexplosive treatment (mass of $\mathrm{Y}_{2} \mathrm{O}_{3}-88.3 \mathrm{mg}$; mass of aluminum foil on which powder was located - $58.9 \mathrm{mg}$; discharge voltage - $2.6 \mathrm{kV}$ ) with subsequent electron beam irradiation (energy density 
of electron beam - $25 \mathrm{~J} / \mathrm{cm}^{2}$ ) by methods of scanning and transmission electron microscopy. The main investigations in the research were performed by methods of transmission electron microscopy. Changes in tribological properties and microhardness under the given parameters of treatment were considered in detail in paper $^{21}$.

\section{Material and Methods of Research}

Al-11wt \% Si alloy whose chemical composition is shown in Table 1 was used as a material under study. The samples of the alloy were divided into three groups: (1) in the cast state; (2) after irradiation by the pulsed electron beam; (3) after the complex treatment. The irradiation of samples of selected alloy by pulsed electron beam (PEB) was done at the specialized equipment $\mathrm{SOLO}^{21}$. The parameters of the electron beam are the following: energy of the electrons $-17 \mathrm{keV}$, energy density of electron beam $-25 \mathrm{~J} / \mathrm{cm}^{2}$, the pulse length $-150 \mu \mathrm{s}$, number of pulses -3 , frequency of pulses $-0.3 \mathrm{~s}^{-1}$, pressure of the argon in working chamber $-2 \cdot 10^{-2} \mathrm{~Pa}$. The complex modification of Al- $11 \mathrm{wt} \% \mathrm{Si}$ alloy surface layer was performed by the combination of electroexplosion alloying (the first stage of treatment) and irradiation by pulsed electron beam (the second stage of treatment). The electroexplosion alloying (further EEA) was performed by yttrium oxide powder (mass of $\mathrm{Y}_{2} \mathrm{O}_{3}-88.3 \mathrm{mg}$; mass of aluminum foil on which powder was located $-58.9 \mathrm{mg}$; discharge voltage $-2.6 \mathrm{kV}$ ). The regime of subsequent irradiation by pulsed electron beam is mentioned in Zaguliaev et al. ${ }^{21}$.

Using the scanning and transmission electron microscopes (the devices Philips SEM-515 with the microanalyzer EDAX ECON IV and JEM-2100F) as well as the mapping method $^{22}$ the elemental and phase compounds, the state of defect substructure ${ }^{23}$ were examined. The friction properties such as the wear resistance and friction factor were performed tested at tribometers "Pin on Disc" and "Oscillating TRIBOtester". As a counter body the ball in

Table 1. Chemical composition (weight. \%) of Al- $11 \mathrm{wt} \% \mathrm{Si}$ alloy determined by X-ray microanalysis method.

\begin{tabular}{crrrrrrrr}
\hline $\mathrm{Al}$ & $\mathrm{Si}$ & $\mathrm{Cu}$ & $\mathrm{Mg}$ & $\mathrm{Ni}$ & $\mathrm{Fe}$ & $\mathrm{Cr}$ & $\mathrm{Mn}$ & $\mathrm{Ti}$ \\
\hline 84.88 & 11.10 & 2.19 & 0.58 & 0.92 & 0.25 & 0.01 & 0.02 & 0.05 \\
\hline
\end{tabular}

diameter 6 mm made of J19965 steel was used. The track radius was equal to $4 \mathrm{~mm}$. The load of indenter and track length changed depending on the level of wear resistance of the material under research.

For statistical data processing, six samples were tested in each group. Three samples from these, chosen arbitrarily, were tested for wear, and the remaining samples were studied by the structural methods. Then the obtained data were statistically processed. The most typical images of structure are presented in the paper.

Scanning electron microscopy was performed using metallographic sections cut out in the central part of a sample across the surface of irradiation. The sample preparation consisted in grinding, polishing and chemical etching needed for exhibiting the structure.

The foils for studying the structural phase state of the material by the methods of transmission electron microscopy were prepared by ion thinning (device Ion Slicer EM-09100IS) of plates $\sim 100 \mu \mathrm{m}$ thick (h) cut out from the sample by electric spark method. The mode of cutting was chosen in such a way that it introduced no additional deformation and therefore, had no influence on the sample structure.

\section{Results and Discussion}

The friction properties (wear rate - the value inverse to wear resistance of the material and friction factor) of Al-11wt $\% \mathrm{Si}$ alloy were investigated in the cast state, after irradiation by PEB and after the complex treatment combining EEA and PEB. The studies of wear rate have shown that wear resistance of $\mathrm{Al}-11 \mathrm{wt} \% \mathrm{Si}$ alloy subjected to the complex treatment increased by 18 times (from $48 \cdot 10^{-4} \mathrm{~mm}^{3} / \mathrm{N} \cdot \mathrm{m}$ to $2.66 \cdot 10^{-4} \mathrm{~mm}^{3} / \mathrm{N} \cdot \mathrm{m}$ ) compared to wear resistance of alloys in a cast state and increased by 2.6 times (from $7 \cdot 10^{-4} \mathrm{~mm}^{3} / \mathrm{N} \cdot \mathrm{m}$ to $2.69 \cdot 10^{-4} \mathrm{~mm}^{3} / \mathrm{N} \cdot \mathrm{m}$ ) in that of alloy irradiated by the pulsed electron beam. Friction factor decreases by 1.6 time at the combined treatment ( $\mu=0.34)$ relative to the initial material $(\mu=0.55)$ and by 1.3 time relative to the alloy irradiated by intense electron beam $(\mu=0.45)$.

It is evident that the increase in the friction properties of $\mathrm{Al}-11 \mathrm{wt} \% \mathrm{Si}$ alloy is caused by the change in the structural phase state of the material's surface layer. Figure 1a, 1b
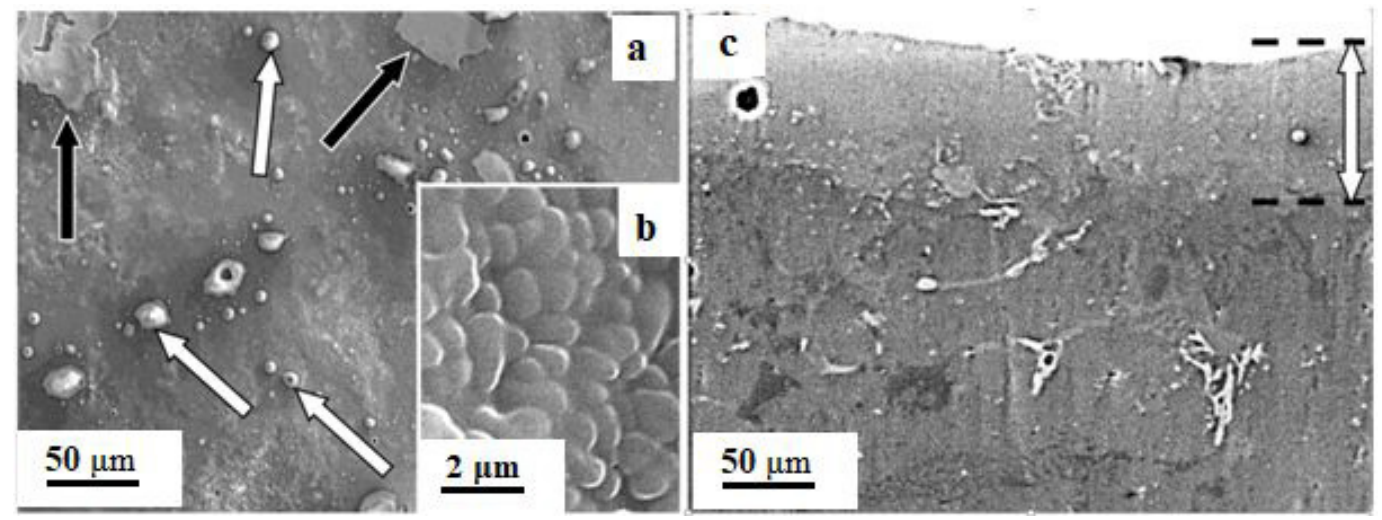

Figure 1. Structure of Al-11wt\%Si alloy subjected to electroexplosion alloying and subsequent irradiation by pulsed electron beam; $\mathrm{a}, \mathrm{b}$ - structure of irradiation surface; $\mathrm{c}$ - structure of transverse etched metallographic section. In (a) the dark arrows designate the films, the light arrows - the microdroplets located on the surface of the sample; in (c) - modified layer. Scanning electron microscopy. 
shows the characteristic electron microscopic images of $\mathrm{Al}-11 \mathrm{wt} \% \mathrm{Si}$ alloy surface structure subjected to the complex treatment. As a result of the complex treatment the relief surface containing the microdroplets and films (Figure 1a) is formed. The modified layer being formed has a submicrocrystalline structure with the dimensions of the crystallites less than $1 \mu \mathrm{m}$ (Figure 1b).

The structure analysis of the etched transverse metallographic sections has shown that the thickness of the modified layer amounts to $70-80 \mu \mathrm{m}$ (Figure 1c).

The elemental compositions, the phase morphology, the state of defect substructure of Al-11wt $\%$ Si alloy surface layer subjected to complex treatment were examined by the methods of transmission electron diffraction microscopy. Figure 2 presents the electron microscopic images of Al-11wt $\%$ Si alloy structure at different distances from the surface of the complex modification.

The analysis of the images presented in Figure 2 shows that in the layer up to $80 \mu \mathrm{m}$ in thickness the structure of cellular crystallization is formed. The dimension of cells varies within the limits from $0.8 \mu \mathrm{m}$ to $1.3 \mu \mathrm{m}$. The cells are separated by the interlayers of the second phase. The thickness of the interlayers varies within the limits of 50-75 $\mathrm{nm}$. The inclusions of the second phase having the faceted shape in the form of cuboid or four-leaf rosettes are located mostly in the triple junctions of the cells' boundaries.
The dimensions of these inclusions vary within the limits of $0.5-0.7 \mu \mathrm{m}$. Thus, the complex treatment combining the EEA and the subsequent irradiation by the PEB results in the formation of the surface layer whose inclusions of the second phase are by tens - hundreds times less than those being present in $\mathrm{Al}-11 \mathrm{wt} \% \mathrm{Si}$ alloy of the cast state.

The distribution of the chemical elements in the surface layer was investigated by the methods of micro- X-ray spectral analysis of thin foils. The results of the elemental analysis (the method of mapping of the layer adjacent to the surface of modification) are presented in Figure 3 and in Table 2. It is clearly seen that the interlayers located along the boundaries of high crystallization cells are enriched by the atoms of silicon and yttrium. The particles of the faceted shape are enriched by titanium atoms. The yttrium atoms form the thin foils and the droplets located on the surface of the sample's modification.

In a quantitative sense, the elemental composition of the surface layer, whose image is shown in Figure 3a, is presented in Table 2. When analyzing the results of the table it may be noted that the main chemical element of the layer under study is aluminum whose mass fraction increases $75 \%$. The concentration of the revealed alloying elements varies within the limits from 1 mass $\%$ to 5 mass $\%$.

The elemental composition of the modified layer detected by the methods of electron microscopy of thin
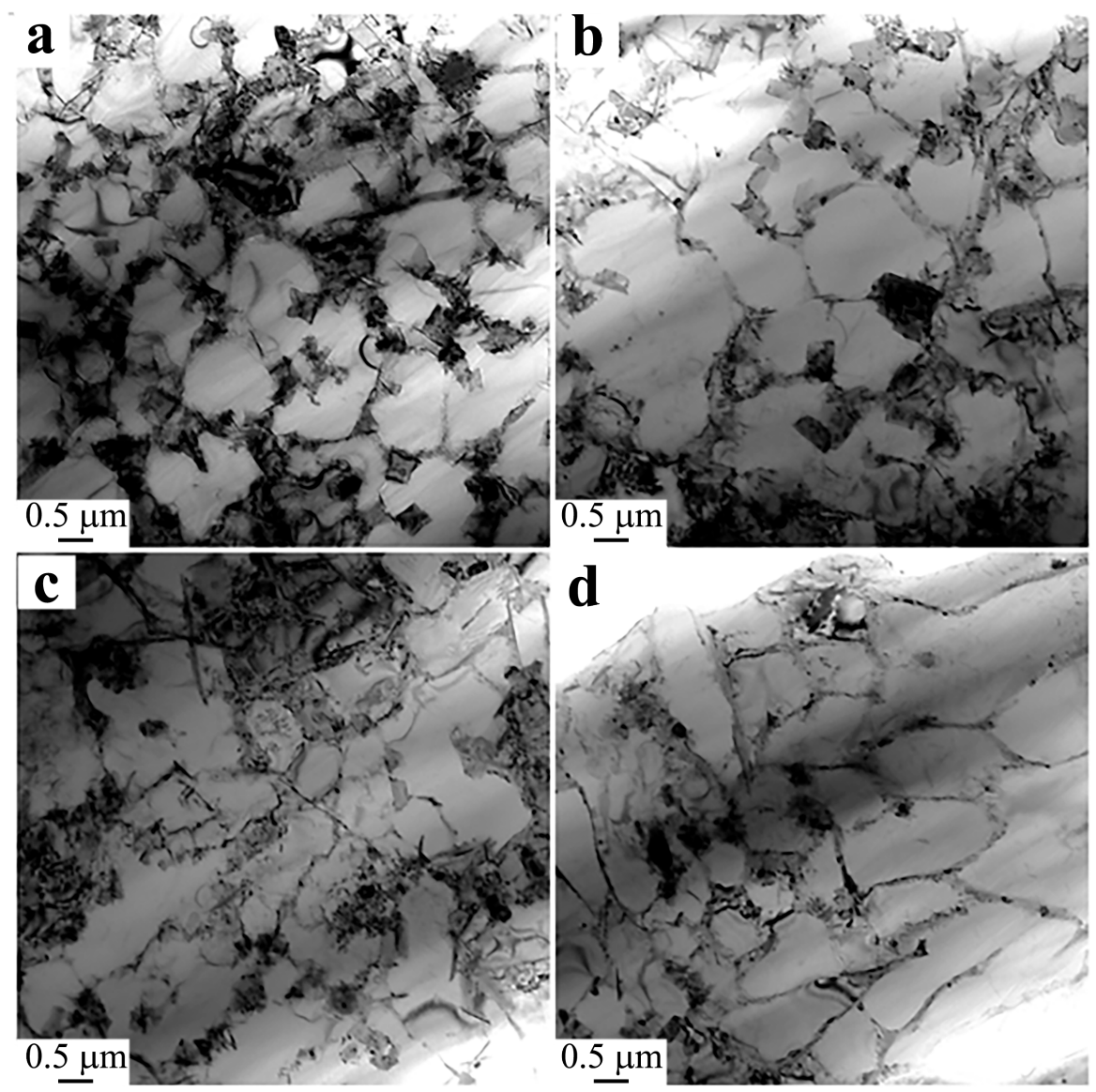

Figure 2. Structure of Al-11wt\%Si alloy subjected to complex modification: a - d - layers located at distances of $20 \mu \mathrm{m} ; 40 \mu \mathrm{m}, 65 \mu \mathrm{m}$, $80 \mu \mathrm{m}$ from the surface of treatment, respectively. 

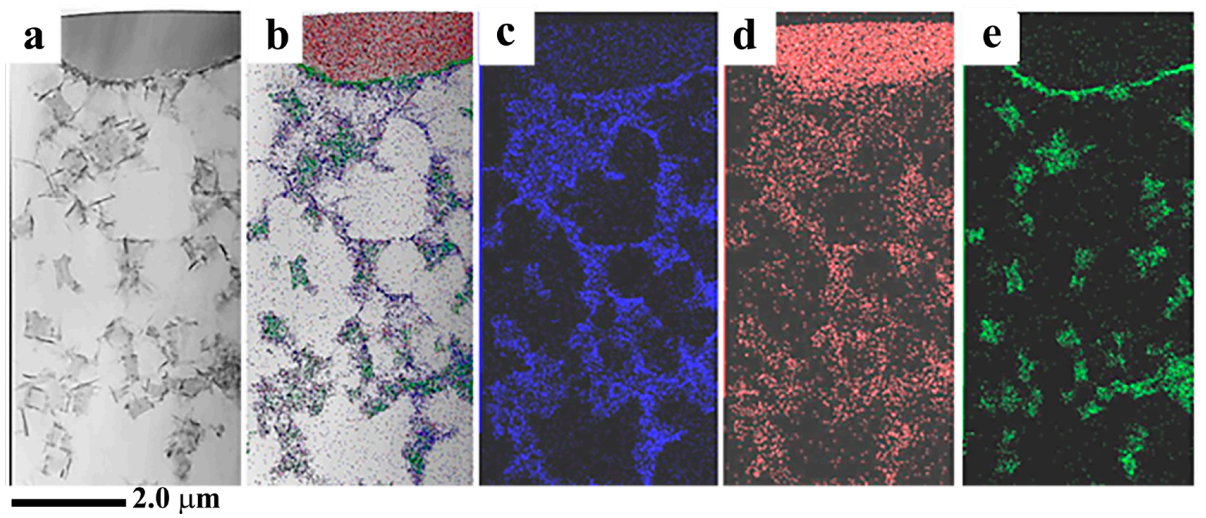

Figure 3. Bright-field electron microscopic image of structure of surface layer of modified Al-11wt $\%$ Si alloy (a); c-e - images of the given layer formed in the characteristic X-ray radiation of silicon atoms (c), yttrium (d) and titanium (e); the image (b) is formed by superimposing of images (c-e) on (a).

Table 2. Chemical composition of Al- $11 \mathrm{wt} \% \mathrm{Si}$ alloy subjected to complex treatment combining the electroexplosion alloying and the subsequent irradiation by pulsed electron beam.

\begin{tabular}{|c|c|c|c|c|c|}
\hline Element & $\mathrm{keV}$ & Mass, $\%$ & Counts & Error, \% & Atom, $\%$ \\
\hline $\mathrm{O}$ & 0.525 & 2.30 & 10875.08 & 0.11 & 4.17 \\
\hline $\mathrm{Mg}$ & 1.253 & 1.13 & 9213.72 & 0.20 & 1.35 \\
\hline Al (Ref.) & 2.486 & 75.76 & 626449.69 & 0.00 & 81.60 \\
\hline $\mathrm{Si}$ & 1.739 & 5.01 & 43060.93 & 0.05 & 5.18 \\
\hline $\mathrm{Ti}$ & 4.508 & 5.14 & 33403.07 & 0.06 & 3.12 \\
\hline $\mathrm{Fe}$ & 6.398 & 2.49 & 13508.27 & 0.16 & 1.30 \\
\hline $\mathrm{Ni}$ & 7.471 & 1.07 & 5163.90 & 0.48 & 0.53 \\
\hline $\mathrm{Cu}$ & 8.040 & 3.33 & 14151.06 & 0.19 & 1.52 \\
\hline $\mathrm{Y}$ & 1.922 & 3.78 & 8101.01 & 0.34 & 1.23 \\
\hline Total & & 100 & & & 100 \\
\hline
\end{tabular}

foils depends on the distance (X) from the surface of treatment as follows from the analysis of the results presented in Figure 4. The concentration of oxygen, yttrium and titanium atoms decreases substantially as the distance from the surface of treatment increases, and at a distance of $80 \mu \mathrm{m}$ it is approximate to zero. Maximum concentration of oxygen, yttrium and titanium atoms is observed in the layer most closely adjacent to the treatment surface (up to $5 \mu \mathrm{m}$ ).

The phase composition of Al- $11 \mathrm{wt} \% \mathrm{Si}$ alloy's modified layer was analyzed using the dark-field images and the techniques of interpretation of microelectron diffraction patterns. Figure 5, a shows the electron beam bright-field image of the surface layer of modified alloy.

The microelectron diffraction pattern formed in the foil's region selected by the selective diaphragm (Figure 5b) contains the diffraction halo corresponding to the amorphous state of the substance and the diffraction reflections forming the rings (Figure $5 \mathrm{c}$ ). The analysis of the microelectron diffraction pattern enabled to detect the reflections of silicon and yttrium silicide (SiY). Following the results of micro X-ray spectral analysis of the foil's region presented in Figure 3d it may be suggested that the amorphous phase is the region of the sample's surface (the film or droplet) enriched by yttrium. One of the phases having a nanocrystalline structure and located along the interface of the droplet and the main volume of the sample is $(\mathrm{SiY})$ yttrium silicide.

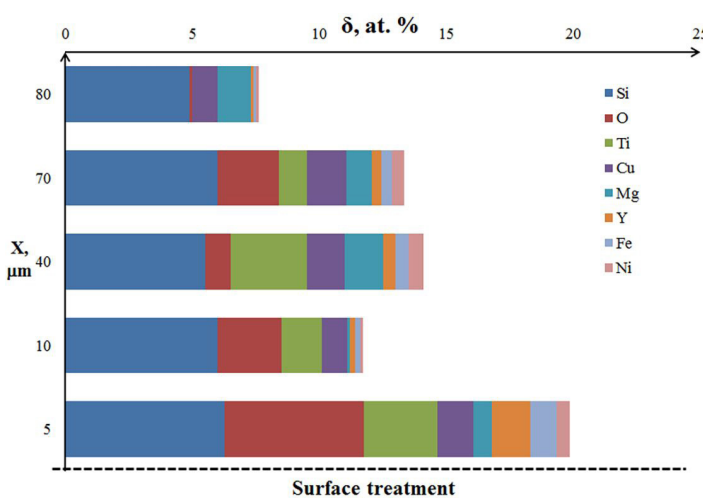

Figure 4. Dependence of concentration of Al-11wt\%Si alloy chemical elements (excluding aluminium) subjected to complex treatment on distance $(\mathrm{X})$ from the surface of modification.

Electron microscopic image of cellular crystallization structure is presented in Figure 6. It is clearly seen that the volume of the high-velocity crystallization cells is formed by the solid solution based on the crystal lattice of aluminum. The interlayers separating the crystallization cells contain the particles of silicon.

The electron microscopic image of the particles having the shape of four-leaf rosettes is presented in Figure 7. It is shown by the methods of dark-field analysis that these particles are $\alpha$-titanium. 

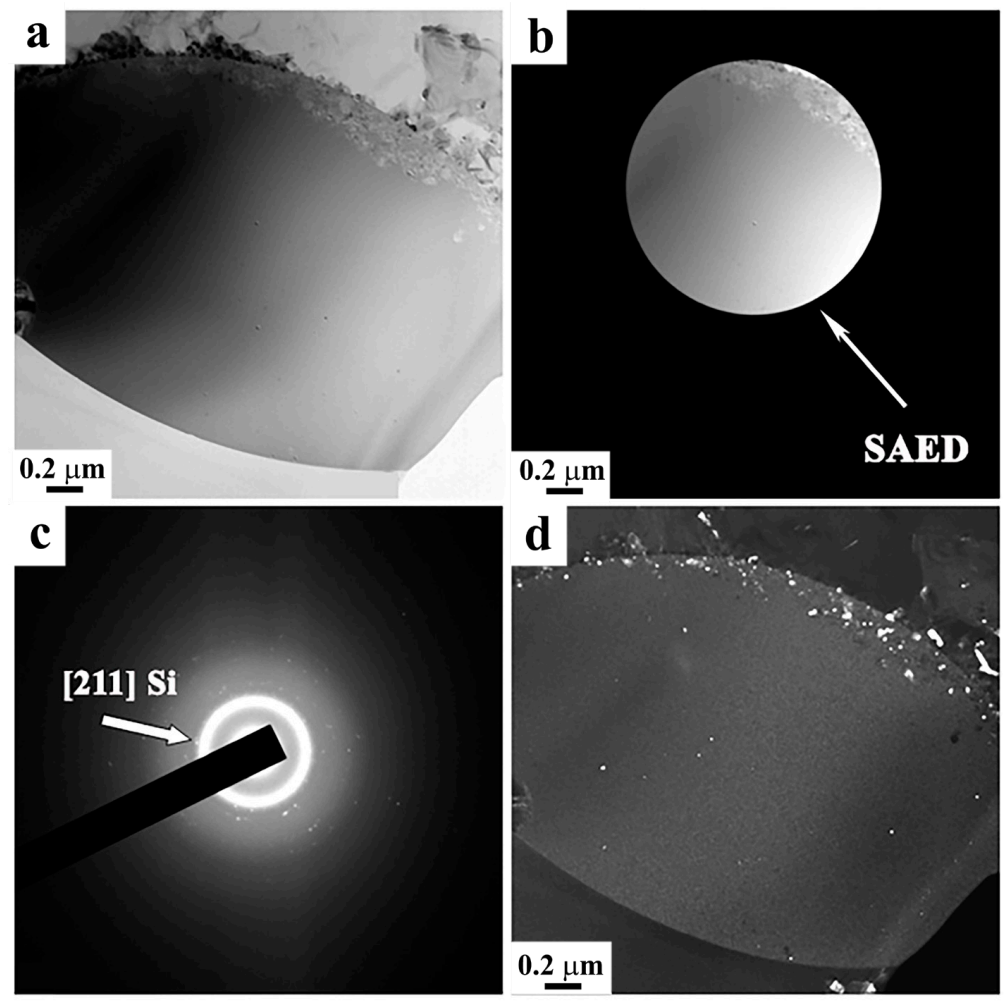

Figure 5. Electron microscopic image of Al-11wt\%Si alloy's surface layer structure subjected to electroexplosion alloying and subsequent irradiation by pulsed electron beam; $\mathrm{a}$ - bright fields and b - bright fields with SAED; $\mathrm{c}$ - selected area electron diffraction (the arrow designates the reflection of dark field formation); $d$ - dark field formed in reflection [211] of Si.
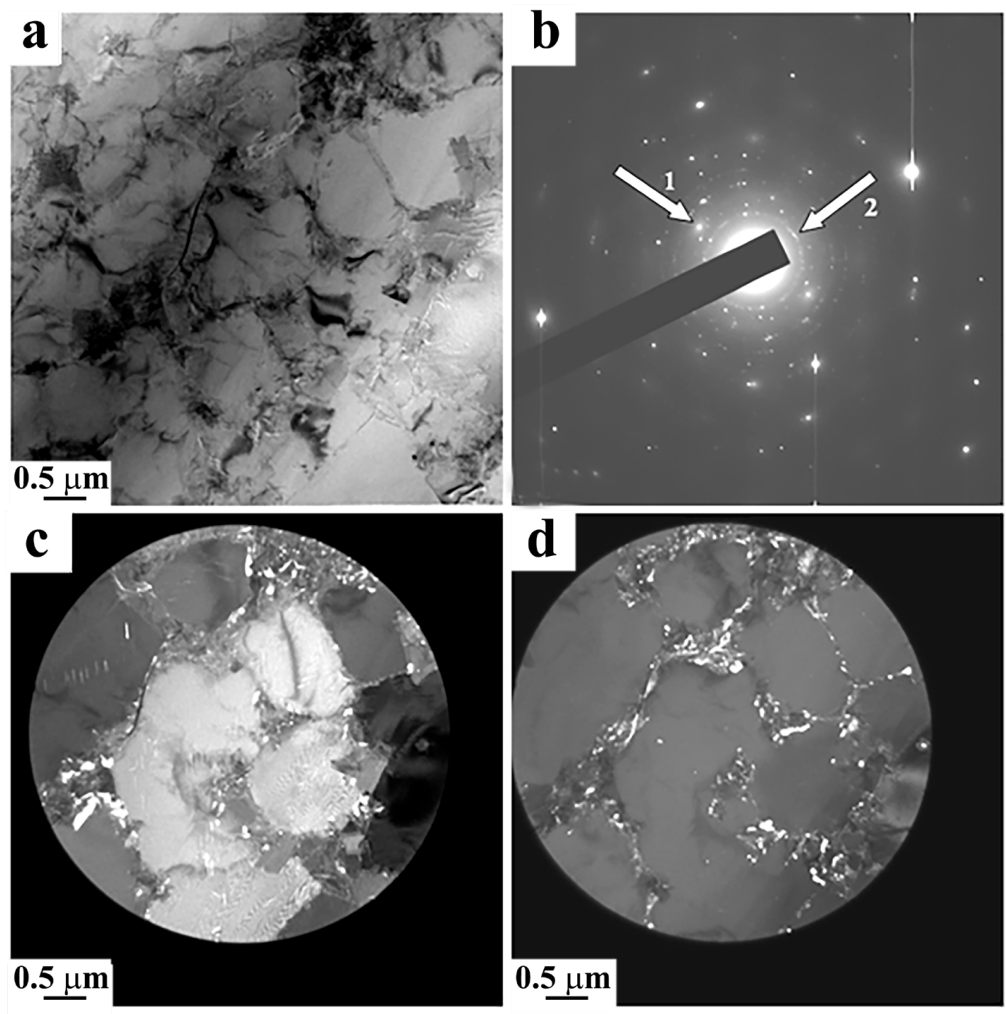

Figure 6. Electron microscopic image of cellular crystallization structure of Al-11wt $\% \mathrm{Si}$ alloy's surface layer subjected to electroexplosion alloying and subsequent irradiation by intense pulsed electron beam; $a-$ bright field; $b$ - selected area electron diffraction (the arrows designate the reflections of dark field formation: 1 - c, 2 - d; c, d - dark fields formed in reflections [111] $\mathrm{Al}$ (c) and [111] Si (d), respectively. 

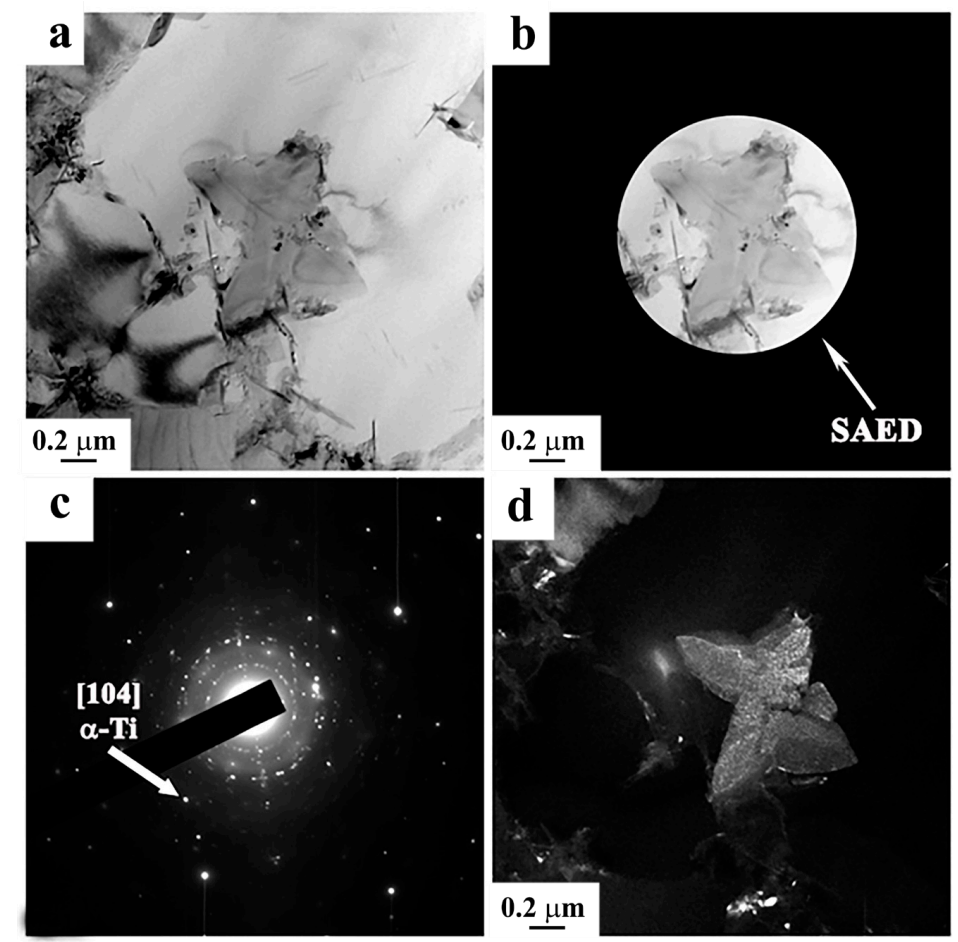

Figure 7. Electron microscopic image of Al-11wt\%Si alloy's surface layer structure subjected to electroexplosion alloying and subsequent irradiation by pulsed electron beam; a - bright fields and b - bright fields with SAED; $\mathrm{c}$ - selected area electron diffraction (the arrow designates the reflection of dark field formation); $d$ - dark field formed in reflections [104] $\alpha$-Ti (d).

\section{Conclusion}

The research into the elemental and phase compounds, the state of defect substructure has been done and the friction properties of $\mathrm{Al}-11 \mathrm{wt} \% \mathrm{Si}$ alloy subjected by the complex treatment combining the electroexplosion alloying and the subsequent irradiation by pulsed electron beam have been carried out. It has been shown that the multielemental multiphase layer $\approx 80 \mu \mathrm{m}$ thick having the submicro-nanocrystalline structure is formed as a result of the Al-11wt\% Si alloy's complex treatment. It has been detected that the droplets enriched by yttrium atoms being in the amorphous state are present on the surface of modification. It has been shown that the high-velocity crystallization of the alloyed surface layer is accompanied by the formation of $\alpha$-titanium particles in the shape of cuboids and four-leaf rosettes. It has been established that the complex surface treatment of Al-11 wt $\% \mathrm{Si}$ cast alloy results in the multiple increase (by 18 times) in wear resistance and the decrease (by 1.6 times) in friction factor of the modified layer.

\section{Acknowledgements}

The research was financially supported by the Russian Science Foundation (RSF) (project No 19-79-10059).

\section{References}

1. Sigworth GK. The modification of Ai-Si casting alloys: important practical and theoretical aspects. Int J Met Cast. 2008;2(2):1940. http://dx.doi.org/10.1007/BF03355425.
2. Kaufman JG, Rooy EL. Aluminum alloy castings: properties, processes, and applications. Materials Park: ASM International. 2004.

3. Mann VK, Alabin AN, Krokhin AY, Frolov AV, Belov NA. New generation of high strength aluminum casting alloys. Light Metal Age. 2015;73:44-7.

4. Krishnan PK, Christy JV, Arunachalam R, Mourad A-HI, Muraliraja R, Al-Maharbi M, et al. Production of aluminum alloy-based metal matrix composites using scrap aluminum alloy and waste materials: influence on microstructure and mechanical properties. J Alloys Compd. 2019;784:1047-61. http://dx.doi.org/10.1016/j.jallcom.2019.01.115.

5. Su MN, Young B. Material properties of normal and high strength aluminium alloys at elevated temperatures. Thin-walled Struct. 2019;137:463-71. http://dx.doi.org/10.1016/j.tws.2019.01.012.

6. Nimura K, Sugawara T, Jibiki T, Ito S, Shima M. Surface modification of aluminum alloy to improve fretting wear properties. Tribol Int. 2016;93:702-8. http://dx.doi.org/10.1016/j. triboint.2015.01.022.

7. Pervikov A, Lozhkomoev A, Bakina O, Lerner M. Synthesis of core-shell and Janus-like nanoparticles by non-synchronous electrical explosion of two intertwined wires from immiscible metals. Solid State Sci. 2019;87:146-9. http://dx.doi.org/10.1016/j. solidstatesciences.2018.11.016.

8. Romanov DA, Sosnin KV, Gromov VE, Bataev VA, Ivanov YF, Glezer AM, et al. Titanium-zirconium coatings formed on the titanium implant surface by the electroexplosive method. Mater Lett. 2019;242:79-82. http://dx.doi.org/10.1016/j. matlet.2019.01.088.

9. Abrosimova G, Matveev D, Pershina E, Aronin A. Effect of treatment conditions on parameters of nanocrystalline structure in Al-based alloys. Mater Lett. 2016;183:131-4. http://dx.doi. org/10.1016/j.matlet.2016.07.053. 
10. Selyanin IF, Deev VB, Belov NA, Prikhodko OG, Ponomareva KV. Physical modifying effects and their influence on the crystallization of casting alloys. Russ J Non-Ferrous Met. 2015;56(4):434-6. http://dx.doi.org/10.3103/S1067821215040197.

11. Moskvina VA, Astafurova EG, Ramazanov KN, Maier GG, Astafurov SV, Melnikov EV, et al. A role of initial microstructure in characteristics of the surface layers produced by ion-plasma treatment in CrNiMo austenitic stainless steel. Mater Charact. 2019;153:372-80. http://dx.doi.org/10.1016/j. matchar.2019.05.029.

12. Konovalov S, Komissarova I, Ivanov Y, Gromov V, Kosinov D. Structural and phase changes under electropulse treatment of fatigue-loaded titanium alloy VT1-0. J. Mat. Res. Techn. 2019;8(1):1300-7. http://dx.doi.org/10.1016/j.jmrt.2018.09.008.

13. Surzhikov AP, Frangulyan TS, Ghyngazov SA, Vasil'ev IP, Chernyavskii AV. Sintering of zirconia ceramics by intense high-energy electron beam. Ceram Int. 2016;42(12):13888-92. http://dx.doi.org/10.1016/j.ceramint.2016.05.198.

14. Panin SV, Maruschak PO, Vlasov IV, Sergeev VP, Ovechkin BB, Neifeld VV. Impact toughness of $12 \mathrm{Cr} 1 \mathrm{MoV}$ steel. Part 2 - Influence of high intensity ion beam irradiation on energy and deformation parameters and mechanisms of fracture. Theor Appl Fract Mech. 2016;83:82-92. http://dx.doi.org/10.1016/j. tafmec.2015.12.009.

15. Tang G, Luo D, Tang S, Mu Q, Wang L, Ma X. The microstructure and properties of $\mathrm{Cr}$ alloying layer after surface alloying treatment induced by high current pulsed electron beam. J Alloys Compd. 2017;714:96-103. http://dx.doi.org/10.1016/j. jallcom.2017.04.014.

16. Jung A, Buchwalder A, Hegelmann E, Hengst P, Zenker R. Surface engineering of spray-formed aluminium-silicon alloys by plasma nitriding and subsequent electron beam remelting.
Surf Coat Tech. 2018;335:166-72. http://dx.doi.org/10.1016/j. surfcoat.2017.12.016.

17. Ding S, Xue M, Wu R, Lai Y, Men Y, Kong X, et al. Electron beam reduction induced by self-assembly growth of $\mathrm{Co} / \mathrm{CoO}$ nanocomposite materials. J Alloys Compd. 2018;744:615-20. http://dx.doi.org/10.1016/j.jallcom.2018.02.033.

18. Zagulyaev DV, Konovalov SV, Gromov VE, Glezer AM, Ivanov YF, Sundeev RV. Structure and properties changes of Al-Si alloy treated by pulsed electron beam. Mater Lett. 2018;229:377-80. http://dx.doi.org/10.1016/j.matlet.2018.07.064.

19. Konovalov SV, Zagulyaev DV, Ivanov YF, Gromov VE. Effect of yttrium oxide modification of Al-Si alloy on microhardness and microstructure of surface layers. Metalurgija. 2018;57:253-6.

20. Ivanov Y, Gromov V, Zaguliaev D, Glezer A, Sundeev R, Rubannikova Y, et al. Modification of surface layer of hypoeutectic silumin by electroexplosion alloying followed by electron beam processing. Mater Lett. 2019;253:55-8. http:// dx.doi.org/10.1016/j.matlet.2019.05.148.

21. Zaguliaev D, Konovalov S, Ivanov Y, Gromov V, Petrikova E. Microstructure and mechanical properties of doped and electron-beam treated surface of hypereutectic Al-11.1\% $\mathrm{Si}$ alloy J. Mater. Res. Technol. 2019;8(5):3835-42. http://dx.doi. org/10.1016/j.jmrt.2019.06.045.

22. Kawałko J, Bobrowski P, Koprowski P, Jarzebska A, Bieda M, Lagoda M, et al. Microstructure evolution of CP titanium during deformation in KoBo process followed by cold rolling. $\mathrm{J}$ Alloys Compd. 2017;707:298-303. http://dx.doi.org/10.1016/j. jallcom.2016.11.202.

23. Inkson BJ. Scanning electron microscopy (SEM) and transmission electron microscopy (TEM) for materials characterization. Mater. Characterization Using Nondestructive Evaluation (NDE). Methods. 2016;2016:17-43. 